\title{
Correction to: Extreme Atherosclerotic Cardiovascular Disease (ASCVD) Risk Recognition
}

\author{
Paul D. Rosenblit ${ }^{1,2,3}$
}

Published online: 6 November 2019

(C) Springer Science+Business Media, LLC, part of Springer Nature 2019

\section{Correction to: Current Diabetes Reports (2019) 19: 61} https://doi.org/10.1007/s11892-019-1178-6

The original version of this article unfortunately contained a mistake. In Table 1, in the footnote section:

“†Unique primary preven5on se6ng of 'extreme' ASCVD risk" should read: "†Unique primary prevention setting of 'extreme' ASCVD risk"

The online version of the original article can be found at https://doi.org/ 10.1007/s11892-019-1178-6

\section{Paul D. Rosenblit}

pdrosenblit@yahoo.com

1 Department Medicine, Division Endocrinology, Diabetes, Metabolism, University California, Irvine (UCI), School of Medicine, Irvine, CA 92697, USA

2 Diabetes Out-Patient Clinic, UCI Medical Center, Orange, CA 92868, USA

3 Diabetes/Lipid Management \& Research Center, 18821 Delaware St., Suite 202, Huntington Beach, CA 92648, USA 